\title{
Association between perceived neighbourhood characteristics, physical activity and diet quality: results of the Brazilian Longitudinal Study of Adult Health (ELSA-Brasil)
}

Dóra Chor ${ }^{1 *}$, Letícia Oliveira Cardoso ${ }^{1}$, Aline Araújo Nobre², Rosane Härter Griep ${ }^{3}$, Maria de Jesus Mendes Fonseca ${ }^{1}$, Luana Giatti ${ }^{4}$, Isabela Bensenor ${ }^{5}$, Maria del Carmen Bisi Molina ${ }^{6}$, Estela M. L. Aquino ${ }^{7}$, Ana Diez-Roux ${ }^{8}$, Débora de Pina Castiglione ${ }^{9}$ and Simone M. Santos ${ }^{1}$

\begin{abstract}
Background: The study explores associations between perceived neighbourhood characteristics, physical activity and diet quality, which in Latin America and Brazil have been scarcely studied and with inconsistent results.

Methods: We conducted a cross-sectional analysis of 14,749 individuals who participated in the Brazilian Longitudinal Study of Adult Health (Estudo Longitudinal de Saúde do Adulto, ELSA-Brasil) baseline. The study included current and retired civil servants, aged between 35 and 74 years, from universities and research institutes in six Brazilian states. The International Physical Activity Questionnaire (IPAQ) long form was used to characterize physical activity during leisure time and commuting; additional questions assessed how often fruit and vegetables were consumed, as a proxy for diet quality. Neighbourhood characteristics were evaluated by the "Walking Environment" and "Availability of Healthy Foods" scales originally used in the Multi-Ethnic Study of Atherosclerosis (MESA). Associations were examined using multinomial logistic regression.
\end{abstract}

Results: Perceiving a more walkable neighbourhood was positively associated with engaging in leisure time physical activity and doing so for longer weekly. Compared with those who saw their neighbourhood as less walkable, those who perceived it as more walkable had 1.69 (95\% Cl 1.57-1.83) and 1.39 (1.28-1.52) greater odds of engaging in leisure time physical activity for more than $150 \mathrm{~min} /$ week or up to $150 \mathrm{~min} /$ week (vs. none), respectively. Perceiving a more walkable neighbourhood was also positively associated with transport-related physical activity. The same pattern was observed for diet: compared with participants who perceived healthy foods as less available in their neighbourhood, those who saw them as more available had odds 1.48 greater (1.31-1.66) of eating fruits, and 1.47 greater (1.30-1.66) of eating vegetables, more than once per day.

Conclusions: Perceived walkability and neighbourhood availability of healthy food were independently associated with the practice of physical activity and diet quality, respectively, underlining the importance of neighbourhood-level public policies to changing and maintaining health-related habits.

Keywords: Neighbourhood, Physical activity, Diet, Food environment, Public health

\footnotetext{
* Correspondence: dorachor@fiocruz.br

${ }^{1}$ Escola Nacional de Saúde Pública, Fundação Oswaldo Cruz, Rio de Janeiro,

RJ, Brazil

Full list of author information is available at the end of the article
} 


\section{Background}

In Brazil's state capitals, only $34 \%$ of the adult population engage in open-air physical activity for the recommended length of time ( $\geq 150$ min per week), while only $24 \%$ consume at least five portions of fruit and vegetables on five or more days per week, one of the indicators of a healthy diet [1]. Physical activity is an important determinant of health and body weight, and is associated with the incidence of diabetes and cardiovascular diseases [2, 3]. In older adults, there is evidence that physical activity postpones functional decline [4] and dementia [5]. Unhealthy diets are associated with major public health problems, such as obesity, cardiovascular diseases and diabetes, both in Brazil and worldwide [6, 7].

Abel \& Frohlich [8] posit that life chances (structure) and choice-based life conduct (agency) are jointly involved in shaping health-related choices and that the neighbourhood can be a place that fosters behavioural (or attitudinal) change. Investigations into how residential environment or neighbourhood characteristics influence health are important in generating empirical evidence to inform public policies based on the rationale that choice of health habits is not solely the individual's responsibility, but is strongly related to constraints imposed by lack of material resources and by specific social groups' behavioural norms $[9,10]$.

In recent decades, several epidemiological studies have described the effects of neighbourhood characteristics on health-related behaviour that affect morbidity and mortality [11-14]. Although the specific mechanisms that may explain the effect of neighbourhood on healthrelated behaviour are not yet clearly established, there is evidence that easier access to healthy diet and neighbourhoods that offer conditions conducive to engaging in physical activity do increase the likelihood of healthy habits [11, 15-17].

One of the major challenges in studying the effects of neighbourhood on patterns of health-related behaviour, including physical activity and diet quality, is to identify what characteristics may be associated with such behaviour. Given that this literature is still sparse in middleincome countries, such as Brazil, it is important to evaluate a range of characteristics - e.g., traffic, the presence of people exercising -by means of an instrument used previously in another context, the Multi-Ethnic Study of Atherosclerosis (MESA) [18, 19]. In addition, objective and/or perceived measures of neighbourhood characteristics have been used, with both presenting advantages and limitations [19-22]. For example, the measurement of types of food stores present in the areas in which participants live may be an important and useful tool for describing the food environment. However, important dimensions of access that are key factors in environment-diet relationship such as affordability, food choice and acceptability can only be assessed by participants report. Similarly, actual crime rates appear to be a worse predictor of physical inactivity than fear of crime. A limitation of perceived measures, on the other hand, is the possibility of reporting bias generated by reports of neighbourhood conditions and self-reported outcomes. In this study, we use the study population's perception of their neighbourhood's characteristics, because these can "operate as key pathway linking objective neighbourhood material circumstances to health" [20].

Previous studies of the association between neighbourhood characteristics and physical activity and consumption of healthy foods have yielded inconsistent results. We performed a cross-sectional analysis of the relation between perceived neighbourhood characteristics and these two types of behaviour in the baseline results of the Longitudinal Study of Adult Health (Estudo Longitudinal de Saúde do Adulto, ELSA-Brasil), a multicentre cohort study to investigate the development of chronic diseases, particularly cardiovascular disease and diabetes. Our hypotheses were: 1) participants who perceive characteristics that favour physical activity in their neighbourhood engage in more leisure-time, and to a lesser extent transport-related, physical activity; and 2) participants who perceive greater healthy food availability in their neighbourhood consume more fruit and vegetables.

\section{Methods \\ Study participants}

The details of the ELSA-Brasil - including design, eligibility criteria, sources and methods of recruitment and participant characteristics - have been described in detail elsewhere $[23,24]$. Briefly, it is a multicentre cohort study designed to estimate the incidence of cardiovascular diseases and diabetes, as well as their main social, environmental, occupational and biological determinants. It involves civil servants at teaching and research institutions in six Brazilian cities (Rio de Janeiro, São Paulo, Vitória, Belo Horizonte, Bahia and Porto Alegre). All active or retired employees of the six institutions aged 35 to 74 years were eligible for the study. Baseline assessment took place from August 2008 to December 2010 and consisted of an approximately 7-hour evaluation, which included in-person interviews conducted by trained personnel and a comprehensive set of examinations and measurements such as transthoracic echocardiography, carotid artery intima-media thickness and retinal fundus photography besides the more usual ones as oral glucose tolerance test, anthropometry and blood pressure measurement $[25,26]$. The study was approved by the Research and Ethics Committees of the institutions involved - Oswaldo Cruz Foundation and the federal universities of Bahia, Espirito Santo, Minas Gerais, 
and Rio Grande do Sul; and the University of Sao Paulo. All participants signed declarations of informed consent.

For the baseline of this cohort study, all active or retired employees of the six institutions aged $35-74$ years were eligible for the study, totalling, in 2008, 52137 potential participants. As a cohort study (which is now beginning its wave three of data collection), we estimated a sample size which would be sufficient to its main objectives. Sample size estimation was based on the main study outcomes-type 2 diabetes and myocardial infarction (cardiovascular disease). In order to present gender-specific analyses and allow for possible losses to follow-up, we defined the desired sample size as approximately 15,000 persons. Efforts were made to recruit similar proportions of men and women as well as predefined proportions of age groups and occupational categories. From a total of 16435 who expressed interest in participation, 15821 were pre-enrolled, gave written consent, responded to an initial interview and were scheduled for the baseline examination. Only 716 (4.5\%) of those pre-enrolled did not complete the baseline examination. A total of 15,105 participants were enrolled; this study comprised 14,749 participants with complete data on all variables of interest.

\section{Data collection}

\section{Exposure assessment}

The scales used to evaluate neighbourhood characteristics - originally used in the Multi-Ethnic Study of Atherosclerosis (MESA) [18] - were adapted to Brazilian Portuguese in connection with the ELSA-Brasil study [27]. These instruments record respondents' perceptions with regard to social and physical characteristics of their neighbourhood environment. Interviewees were asked to think about their neighbourhood as follows: "By neighbourhood we mean the area around where you live and around your house. It may include places you shop, religious or public institutions, or the local business district. It is the general area around your house where you might perform routine tasks, such as shopping, going to the park, or visiting neighbours".

The two scales applied to these analyses were: 1) Walking Environment (nine items) and 2) Availability of Healthy Foods (four items) (Additional file 1). Response values ranged from 1 to 5 (agree completely to disagree completely). In the Brazilian context [27] and in international studies $[28,29]$, these scales displayed appropriate psychometric properties with Cronbach's alpha's ranging from 0.60 to 0.94 and with test-retest correlations ranging from 0.78 to 0.91 .

On the scale evaluating walkability in ELSA-Brasil, scores varied from 9 (perception of better quality) to 45 (perception of worse quality). Based on the distribution of the responses to each item of the scale, a cut-off score of 18 was applied to divide the two groups: perception of "better walkability" (score $\leq 18$ ) and "worse walkability" (score $>18$ ). That cut-off point has been chosen because it was considered the best to separate two different groups: scores of less than 18 mean that most of the responses for that scale varied between 'agree completely' and 'agree partly', indicating the 'better walkability' group, whereas scores of 18 or more concentrated most of the responses that indicated 'worse walkability'. The same criterion was applied to the scale evaluating neighbourhood availability of healthy foods, with scores varying between 4 (perception of better quality) and 20 (perception of worse quality). The cut-off score was set at 8: "better availability" (score $\leq 8)$ and "worse availability" (score $>8$ ).

\section{Outcome assessment}

In the ELSA-Brasil study, the International Physical Activity Questionnaire (IPAQ) long form was used to assess physical activity during leisure time and for transport [30, 31]. The questions about leisure time physical activity cover the weekly frequency and duration of walking and physical activities of moderate or vigorous intensity performed for at least ten minutes at a time. Transport-related questions include frequency and duration of on foot or by bicycle physical activity. For analytical purposes, an approximate measure of the 'regularity' of physical activity was obtained by multiplying the number of days on which physical activity was practised by the duration in minutes. Participants were then classified into three frequency levels: 1) no physical activity; 2) $<150 \mathrm{~min} /$ week; and 3) $\geq 150 \mathrm{~min} /$ week. This cut-off point was chosen for having been recommended by leading institutions in adult health promotion and maintenance [32-34].

Individual consumption of fruit and vegetables was used as a proxy for diet quality and was measured by way of two questions: 'How often do you usually consume fruit?' and 'How often do you eat raw, boiled or sautéed vegetables, excluding potatoes, cassava and yam?' Since 2006, those questions have been routinely used by 'VIGITEL', the Brazilian Risk Factor Surveillance for Non-Transmissible Chronic Diseases by Telephone Survey with good psychometric properties [35]. There were eight response options: 1 ) More than three times a day; 2) Two or three times a day; 3) Once a day; 4) Five to six times a week; 5) Two to four times a week; 6) Once a week; 7) One to three times a month; and 8) Never or almost never. For both questions, responses were grouped into frequency categories: high (twice or more per day); daily (once a day/five to six times a week); weekly (two to four times a week); and rarely (once a week or less). 


\section{Covariable assessment}

The covariables considered were: gender, age, education (<elementary, elementary complete, secondary complete, university graduate, postgraduate) and monthly per capita family income, calculated from the midpoint of the reported net income category divided by the number of people dependent on that income. Given the wide variation in this variable, it was standardised by subtracting the mean value and dividing by the standard deviation. Per capita family income was converted into US dollars using the 2009 Purchasing Power Parity (PPP) conversion factor for private consumption (BRL $1.7=$ USD 1 ), as published annually by the World Bank [36]. Length of time residing in the neighbourhood was measured in years.

\section{Statistical analysis}

Multinomial logistic regression analysis was used to examine the cross-sectional association between the exposure variables (perception of the neighbourhood in terms of walkability and availability of healthy foods) and the outcomes of interest (physical activity and diet). Crude and adjusted associations were computed (model 1: crude; model 2: adjusted for age; model 3: adjusted for age and gender; model 4: adjusted for age, gender and education; model 4: adjusted for age, gender education and standardised income score. Interaction between gender and the exposure variables was tested. The analyses were performed on the nnet library of $\mathrm{R}$ version 2.15 [37].

\section{Results}

Of the participants, 8023 (54\%) were women, 7787 (53\%) had a university degree, median age was 51 years and mean time of residence in the neighbourhood was
17 years (Table 1). Mean monthly per capita family income was BRL 1751.00, corresponding, on Purchasing Power Parity (PPP), to USD 1029.95. Perception of worse walkability was reported more frequently by women (Table 1), by the group with least mean per capita income and varied inversely with education. Thus, 564 (65\%) of those who had not completed elementary education perceived worse walkability, as compared with 2514 ( $46 \%)$ of the postgraduate group. In addition, the group that perceived worse walkability showed lower median age and longer time of residence in the neighbourhood. During leisure time, women, individuals with lower levels of education and lower mean per capita income were the least active or, when they did engage in physical activity, did so for the least time weekly. As for transport, 28 and $24 \%$ of women and men, respectively, reported no physical activity (Table 1). Among those who did engage in transport-related physical activity, most walked and only $5.8 \%$ rode a bicycle (results not shown). Of note, those with higher levels of education and higher mean per capita income were less active than their counterparts with less favourable socioeconomic conditions.

A less consistent pattern was observed for perceived availability of healthy food in the neighbourhood (Table 2). Education was not consistently associated with perceived availability of healthy foods: in the group with less than complete elementary education, 363 (41.8\%) of participants perceived worse availability of healthy food, compared to 1088 (46.4 \%) in university graduates and $2184(40.1 \%)$ in postgraduates. Men, the group with least education and those with less mean per capita income consumed fruit and vegetables less frequently.

Perceived walkability showed a positive association both with engaging in leisure time physical activity and

Table 1 Perceived walkability and weekly physical activity by population characteristics - ELSA-Brasil, 2008-2010 ( $n=14,749)$

\begin{tabular}{|c|c|c|c|c|c|c|c|c|c|}
\hline \multirow[t]{2}{*}{ Characteristics } & \multirow[t]{2}{*}{$n$} & \multicolumn{2}{|c|}{ Perceived walkability } & \multicolumn{3}{|c|}{$\begin{array}{l}\text { Leisure-time physical } \\
\text { activity/week }\end{array}$} & \multicolumn{3}{|c|}{$\begin{array}{l}\text { Transport-related physical } \\
\text { activity/week }\end{array}$} \\
\hline & & Better & Worse & No & $<150 \mathrm{~min}$ & $>=150 \mathrm{~min}$ & No & $<150 \min$ & $>=150 \mathrm{~min}$ \\
\hline \multicolumn{10}{|l|}{ Gender } \\
\hline Women & 8023 & 42.8 & 57.2 & 48.0 & 20.5 & 31.4 & 27.7 & 39.6 & 32.6 \\
\hline Men & 6726 & 44.9 & 55.1 & 37.0 & 23.1 & 40.0 & 24.4 & 39.2 & 36.5 \\
\hline \multicolumn{10}{|l|}{ Education } \\
\hline$<$ Elementary & 869 & 35.1 & 64.9 & 57.9 & 19.7 & 22.4 & 17.3 & 40.4 & 42.3 \\
\hline Elementary & 1002 & 35.3 & 64.7 & 53.3 & 20.7 & 26.0 & 19.1 & 40.9 & 40.0 \\
\hline Secondary & 5091 & 36.1 & 63.9 & 52.0 & 19.5 & 28.5 & 21.5 & 36.8 & 41.6 \\
\hline University graduate & 2345 & 43.8 & 56.2 & 30.5 & 24.4 & 45.1 & 32.4 & 41.6 & 26.0 \\
\hline Postgraduate & 5442 & 53.8 & 46.2 & 42.6 & 21.3 & 36.1 & 28.3 & 39.0 & 32.7 \\
\hline Median age (years) & 51.0 & 52.0 & 51.0 & 51.0 & 52.0 & 52.0 & 51.0 & 51.0 & 52.0 \\
\hline Mean per capita income (R\$) & 1751.00 & 1984.71 & 1569.44 & 1431.50 & 1857.57 & 2074.45 & 1958.87 & 1783.45 & 1555.48 \\
\hline Mean years residence in the neighbourhood & 17.2 & 15.9 & 18.3 & 17.7 & 16.7 & 16.9 & 16.3 & 16.8 & 18.3 \\
\hline
\end{tabular}


Table 2 Perceived availability of healthy food and fruit and vegetable consumption by population characteristics - ELSA-Brasil, 2008-2010

\begin{tabular}{|c|c|c|c|c|c|c|c|c|c|c|c|}
\hline \multirow[t]{2}{*}{ Characteristics } & \multirow[t]{2}{*}{$\mathrm{n}$} & \multicolumn{2}{|c|}{$\begin{array}{l}\text { Perceived availability } \\
\text { of healthy food }\end{array}$} & \multicolumn{4}{|c|}{$\begin{array}{l}\text { Frequency of fruit } \\
\text { consumption }\end{array}$} & \multicolumn{4}{|c|}{$\begin{array}{l}\text { Frequency of vegetable } \\
\text { consumption }\end{array}$} \\
\hline & & Better & Worse & $>$ Once/day & Daily & Weekly & Rare & $>$ Once/day & Daily & Weekly & Rare \\
\hline \multicolumn{12}{|l|}{ Gender } \\
\hline Female & 8023 & 56.7 & 43.3 & 27.9 & 45.3 & 17.6 & 9.2 & 16.9 & 51.3 & 20.9 & 10.9 \\
\hline Male & 6726 & 56.2 & 43.8 & 16.1 & 40.3 & 25.7 & 17.9 & 12.2 & 44.0 & 25.9 & 17.9 \\
\hline \multicolumn{12}{|l|}{ Education } \\
\hline$<$ Elementary & 869 & 58.2 & 41.8 & 19.8 & 36.7 & 21.4 & 22.1 & 14.2 & 32.6 & 29.5 & 23.7 \\
\hline Elementary & 1002 & 55.8 & 44.2 & 18.4 & 38.2 & 23.8 & 19.6 & 13.5 & 35.6 & 28.1 & 22.8 \\
\hline Secondary & 5091 & 54.0 & 46.0 & 18.7 & 42.4 & 23.0 & 16.0 & 13.2 & 42.7 & 26.0 & 18.1 \\
\hline University graduate & 2345 & 53.6 & 46.4 & 20.4 & 45.5 & 22.2 & 11.9 & 13.5 & 49.3 & 24.6 & 12.5 \\
\hline Postgraduate & 5442 & 59.9 & 40.1 & 28.3 & 44.5 & 18.7 & 8.5 & 17.1 & 57.0 & 18.0 & 7.9 \\
\hline Median age (years) & 51.0 & 52.0 & 50.0 & 54.0 & 52.0 & 49.0 & 50.0 & 52.0 & 52.0 & 51.0 & 50.0 \\
\hline Mean per capita income (R\$) & 1751.00 & 1847.10 & 1626.22 & 2071.99 & 1808.04 & 1529.64 & 1371.99 & 1856.81 & 1957.76 & 1535.36 & 1290.80 \\
\hline $\begin{array}{l}\text { Mean years residence in the } \\
\text { neighbourhood }\end{array}$ & 17.2 & 17.5 & 16.8 & 18.1 & 17.2 & 16.3 & 17.2 & 17.6 & 17.0 & 17.1 & 17.9 \\
\hline
\end{tabular}

with its weekly duration (Table 3). Among those who perceived better walkability, the odds of engaging in physical activity for longer than $150 \mathrm{~min} /$ week (vs. not engaging in leisure time physical activity) were 1.69 times greater (95\% confidence interval (CI)1.57-1.83) than among those who perceived worse walkability. The odds of engaging in physical activity for up to $150 \mathrm{~min} /$ week (vs. doing none at all) were 1.40 greater $(95 \% \mathrm{CI}$ 1.28-1.52) among those who perceived better walkability. The interaction term between walkability and gender was not statistically significant $(p=0.13)$. Perceived walkability was positively associated with higher duration of physical activity for transport ( $>150 \mathrm{~min} /$ week). Among those who perceived better walkability, the odds of engaging in physical activity for longer than $150 \mathrm{~min} /$ week (vs. not engaging in transport-related physical activity) were 1.19 times greater (95 \% CI 1.09-1.30) than among those who perceived worse walkability.

The pattern of association between perceived availability of healthy food in the neighbourhood and frequency of consuming fruit and vegetables was similar to that observed for the physical activity variables. Compared with the participants who perceived worse availability, those who perceived better availability of healthy foods had 1.48 times greater odds (95\% CI 1.32-1.66) of consuming fruit more than once a day (vs. rarely) (Table 4). Those who perceived better availability returned adjusted odds 1.47 times greater (95\% CI 1.30-1.67) of consuming vegetables more than once a day (vs. rarely) (Table 5). The interaction term between gender and perceived availability of healthy food was not significant $(p=0.43$ and $p=0.52$ for fruit and vegetables, respectively).

\section{Discussion}

This study of civil servants living in six different cities in Brazil found that perceiving the environment as more favourable to physical activity was associated with leisure-time physical activity (and with that activity being practised for longer weekly durations) and with transport-related physical activity. In the same direction, the perception of better availability of healthy food in the neighbourhood displayed an association with healthier diet represented by greater consumption of fruit and vegetables.

The multiplicity of instruments for measuring neighbourhood characteristics limits comparison among studies and may partly explain reports of lack of association between neighbourhood characteristics and physical activities [38, 39]. In addition, some authors have investigated specific aspects, such as how levels of violence are associated with people's leisure time and transport-related physical activities [40, 41]. In our case, the scale comprises various conditions that may affect the practice of physical activity, such as the presence of clubs, squares, street conditions, heavy traffic and trees [18, 27, 29]. Taking those differences into consideration, our results confirm those reported in compilations of studies in different countries [40, 42, 43] that a positive relation exists between neighbourhood characteristics and physical activities. With regard to leisure time physical activity, additional evidence presented in a population-based study in Seoul, South Korea, showed that satisfaction with security and with the existence of free park and recreation facilities in the neighbourhood was positively associated with vigorous physical activity among women [44]. In the United 
Table 3 Association between perceived walkability and physical activity - ELSA-Brasil, 2008-2010

\begin{tabular}{|c|c|c|c|c|c|c|c|c|}
\hline \multirow[t]{3}{*}{ Variables } & \multicolumn{4}{|c|}{ Leisure-time physical activity } & \multicolumn{4}{|c|}{ Transport-related physical activity } \\
\hline & \multicolumn{2}{|l|}{$<150$} & \multicolumn{2}{|c|}{$>=150$} & \multicolumn{2}{|l|}{$<150$} & \multicolumn{2}{|c|}{$>=150$} \\
\hline & $\overline{\mathrm{OR}}$ & $\mathrm{Cl}(95 \%)$ & $\overline{O R}$ & $\mathrm{Cl}(95 \%)$ & $\overline{O R}$ & $\mathrm{Cl}(95 \%)$ & $\overline{O R}$ & $\mathrm{Cl}(95 \%)$ \\
\hline \multicolumn{9}{|l|}{ Model 1} \\
\hline Walkability (better) & 1.57 & $1.44-1.71$ & 1.98 & $1.84-2.14$ & 1.02 & $0.94-1.11$ & 1.03 & $0.95-1.12$ \\
\hline \multicolumn{9}{|l|}{ Model 2: Model $1+$ age } \\
\hline Walkability (better) & 1.56 & $1.43-1.70$ & 1.97 & $1.83-2.12$ & 1.01 & $0.93-1.10$ & 1.02 & $0.94-1.11$ \\
\hline Age & 1.01 & $1.00-1.01$ & 1.02 & $1.01-1.02$ & 1.01 & $1.00-1.01$ & 1.02 & $1.01-1.02$ \\
\hline \multicolumn{9}{|l|}{ Model 3: Model $2+$ gender } \\
\hline Walkability (better) & 1.56 & $1.43-1.70$ & 1.97 & $1.82-2.12$ & 1.01 & $0.93-1.10$ & 1.01 & $0.93-1.10$ \\
\hline Age & 1.01 & $1.00-1.01$ & 1.02 & $1.01-1.02$ & 1.01 & $1.00-1.01$ & 1.02 & $1.01-1.02$ \\
\hline Gender (male) & 1.46 & $1.34-1.59$ & 1.65 & $1.53-1.77$ & 1.12 & $1.04-1.22$ & 1.27 & $1.17-1.38$ \\
\hline \multicolumn{9}{|l|}{ Model 4: Model 3 + education } \\
\hline Walkability (better) & 1.42 & $1.30-1.55$ & 1.73 & $1.60-1.87$ & 1.07 & $0.99-1.17$ & 1.17 & $1.08-1.28$ \\
\hline Age & 1.01 & $1.01-1.02$ & 1.02 & $1.02-1.02$ & 1.01 & $1.00-1.01$ & 1.02 & $1.01-1.02$ \\
\hline Gender (male) & 1.51 & $1.39-1.65$ & 1.75 & $1.62-1.90$ & 1.11 & $1.02-1.20$ & 1.27 & $1.16-1.38$ \\
\hline Education (Elementary complete) & 1.21 & $0.96-1.54$ & 1.39 & $1.11-1.74$ & 0.94 & $0.73-1.22$ & 0.91 & $0.70-1.18$ \\
\hline (Secondary complete) & 1.31 & $1.08-1.59$ & 1.83 & $1.52-2.20$ & 0.79 & $0.64-0.98$ & 0.94 & $0.76-1.16$ \\
\hline (University graduate) & 2.59 & $2.14-3.15$ & 4.37 & $3.64-5.24$ & 0.57 & $0.47-0.70$ & 0.36 & $0.29-0.44$ \\
\hline (Postgraduate) & 1.78 & $1.44-2.20$ & 2.89 & $2.37-3.51$ & 0.64 & $0.51-0.80$ & 0.56 & $0.45-0.70$ \\
\hline \multicolumn{9}{|l|}{ Model 5: Model 4+income } \\
\hline Walkability (better) & 1.40 & $1.28-1.52$ & 1.69 & $1.57-1.83$ & 1.08 & $0.99-1.17$ & 1.19 & $1.09-1.30$ \\
\hline Age & 1.01 & $1.00-1.01$ & 1.01 & $1.01-1.02$ & 1.01 & $1.00-1.01$ & 1.02 & $1.02-1.03$ \\
\hline Gender (male) & 1.53 & $1.41-1.68$ & 1.80 & $1.66-1.94$ & 1.10 & $1.01-1.20$ & 1.25 & $1.15-1.36$ \\
\hline Education (Elementary complete) & 1.18 & $0.93-1.50$ & 1.34 & $1.07-1.67$ & 0.95 & $0.74-1.23$ & 0.93 & $0.72-1.20$ \\
\hline (Secondary complete) & 1.22 & $1.01-1.48$ & 1.65 & $1.37-1.98$ & 0.81 & $0.66-1.00$ & 0.99 & $0.80-1.22$ \\
\hline (University graduate) & 1.98 & $1.61-2.44$ & 2.98 & $2.46-3.62$ & 0.63 & $0.51-0.78$ & 0.44 & $0.35-0.55$ \\
\hline (Postgraduate) & 1.51 & $1.22-1.87$ & 2.28 & $1.86-2.79$ & 0.68 & $0.54-0.85$ & 0.64 & $0.51-0.80$ \\
\hline Per capita income z-score & 1.22 & $1.15-1.29$ & 1.32 & $1.25-1.38$ & 0.94 & $0.90-0.99$ & 0.87 & $0.83-0.92$ \\
\hline
\end{tabular}

Reference category = no physical activity

Bold data are statistically significative

States, an environment perceived as favourable in terms of aesthetics, street quality, traffic safety and low levels of violence had a positive association on use of public spaces and facilities for recreation and physical activity [45, 46]. In Holland, Jongeneel-Grimen et al. [47, 48] presented strong evidence of a causal relation between neighbourhood-related factors and the practice of physical activity. In Curitiba - a city in Southern Brazil, whose human development index (HDI) is among the country's ten highest [49] - characteristics such as the "existence of interesting things to see in the neighbourhood", "existence of trees in the neighbourhood", "number of positive aesthetic and security attributes in the neighbourhood" showed a positive association with use of public spaces for recreation and leisure [50].

We found that perceptions of the environment as more favourable to physical activity were associated with transport-related physical activity, although the association was weaker than with leisure time physical activity. Also, the association existed only for the longest duration of activity ( $>150 \mathrm{~min} /$ week). Most authors [40, 51, 52], but not all [53], have reported similarly positive associations. In 17 cities (12 countries), Kerr et al. [40] investigated perceived environmental attributes such as residential density, land use mix-access (having easy access to shops, recreational spaces) and traffic and crime safety, which were found to be associated with transport-related physical activity. The results of studies conducted in four Brazilian cities have also shown association, which vary in direction by specific characteristic [54-57]. Our results confirm the existence of the association and suggest that people who perceive better walkability may live in neighbourhoods offering conditions, such as large sidewalks, street 
Table 4 Association between perceived availability of healthy foods and frequency of consumption of fruit - ELSA-Brasil, 2008-2010

\begin{tabular}{|c|c|c|c|c|c|c|}
\hline \multirow{3}{*}{ Variables } & \multicolumn{6}{|c|}{ Consumption of fruit $^{\mathrm{a}}$} \\
\hline & \multicolumn{2}{|c|}{ Weekly } & \multicolumn{2}{|l|}{ Daily } & \multicolumn{2}{|l|}{ High } \\
\hline & $\overline{\mathrm{OR}}$ & $\mathrm{Cl}(95 \%)$ & $\mathrm{OR}$ & $\mathrm{Cl}(95 \%)$ & $\overline{O R}$ & $\mathrm{Cl}(95 \%)$ \\
\hline \multicolumn{7}{|l|}{ Model 1} \\
\hline Neighbourhood availability of healthy foods (better) & 1.01 & $0.91-1.14$ & 1.37 & $1.24-1.52$ & 1.65 & $1.47-1.84$ \\
\hline \multicolumn{7}{|l|}{ Model 2: Model $1+$ age } \\
\hline Neighbourhood availability of healthy foods (better) & 1.02 & $0.91-1.14$ & 1.31 & $1.18-1.45$ & 1.53 & $1.36-1.71$ \\
\hline Age & 1 & $0.99-1.00$ & 1.03 & $1.02-1.04$ & 1.05 & $1.04-1.05$ \\
\hline \multicolumn{7}{|l|}{ Model 3: Model $2+$ gender } \\
\hline Neighbourhood availability of healthy foods (better) & 1.02 & $0.91-1.15$ & 1.32 & $1.19-1.46$ & 1.55 & $1.38-1.74$ \\
\hline Age & 1 & $0.99-1.00$ & 1.03 & $1.02-1.04$ & 1.05 & $1.04-1.06$ \\
\hline Gender (male) & 0.76 & $0.67-0.85$ & 0.45 & $0.4-0.5$ & 0.28 & $0.25-0.32$ \\
\hline \multicolumn{7}{|l|}{ Model 4: Model 3 + education } \\
\hline Neighbourhood availability of healthy foods (better) & 1.02 & $0.91-1.14$ & 1.30 & $1.17-1.44$ & 1.50 & $1.33-1.68$ \\
\hline Age & 1.00 & $0.99-1.01$ & 1.04 & $1.03-1.04$ & 1.06 & $1.05-1.06$ \\
\hline Gender (male) & 0.77 & $0.69-0.87$ & 0.46 & $0.42-0.51$ & 0.28 & $0.25-0.32$ \\
\hline Education (Elementary complete) & 1.24 & $0.94-1.63$ & 1.23 & $0.96-1.58$ & 1.11 & $0.82-1.49$ \\
\hline (Secondary complete) & 1.42 & $1.13-1.78$ & 1.82 & $1.48-2.23$ & 1.56 & $1.23-1.99$ \\
\hline (University graduate) & 1.8 & $1.4-2.33$ & 2.5 & $1.98-3.15$ & 2.11 & $1.61-2.75$ \\
\hline (Postgraduate) & 2.21 & $1.75-2.80$ & 3.56 & $2.88-4.41$ & 4.41 & $3.47-5.62$ \\
\hline \multicolumn{7}{|l|}{ Model 5: Model $4+$ standardised income score } \\
\hline Neighbourhood availability of healthy foods (better) & 1.02 & $0.91-1.14$ & 1.29 & $1.16-1.43$ & 1.48 & $1.32-1.66$ \\
\hline Age & 1 & $0.99-1.01$ & 1.03 & $1.03-1.04$ & 1.05 & $1.04-1.06$ \\
\hline Gender (male) & 0.77 & $0.69-0.87$ & 0.46 & $0.42-0.52$ & 0.29 & $0.25-0.32$ \\
\hline Education (Elementary complete) & 1.24 & $0.94-1.64$ & 1.21 & $0.94-1.56$ & 1.08 & $0.8-1.45$ \\
\hline (Secondary complete) & 1.42 & $1.13-1.78$ & 1.75 & $1.42-2.15$ & 1.46 & $1.15-1.87$ \\
\hline (University graduate) & 1.81 & $1.39-2.36$ & 2.27 & $1.78-2.89$ & 1.8 & $1.36-2.37$ \\
\hline (Postgraduate) & 2.23 & $1.72-2.89$ & 3.06 & $2.42-3.86$ & 3.42 & $2.62-4.46$ \\
\hline Per capita income z-score & 1 & $0.91-1.08$ & 1.12 & $1.04-1.21$ & 1.2 & $1.10-1.30$ \\
\hline
\end{tabular}

Reference category: rarely consumed (once a week or less). ${ }^{a}$ weekly (two to four times a week); daily (once a day/five to six times a week); high (twice or more a day) Bold data are statistically significative

connectivity and safer traffic, that encourage them to walk to and from bus, metro or train stop or, when possible, to walk straight to their destination. Large traffic jams have been a strong motivation for people to leave their cars at home and use public transport, where they can use their travel time to work, read or simply relax. On the other hand, participants with better perceived walkability and less advantageous socioeconomic conditions may walk for transport or mostly, to and from transport, because they live in areas not serviced by public transport, do not own a car or walking is their least expensive option.

In Brazil, the association of food environment on diet quality has been little studied. The results of an ecological study in São Paulo City indicated the density of stores specialising in selling fruit and vegetables was associated positively with regular consumption of such foods [58]. Our results agree with those of the MESA (ELSA-Brasil applied the same neighbourhood evaluation instrument), in which participants living in the areas ranked worst in food availability were 22-35\% less likely to have a healthy diet than those in the bestranked areas [19]. A recent review of studies from various countries found most indicating that perceptions of greater availability, variety and affordability of foods associated directly with consumption of fruit and vegetables [59]. That review reported moderate evidence of a causal relationship between neighbourhood food environment and type of diet, given that some studies found no such association [60, 61].

Theoretical models able to elucidate the complex mechanisms that relate environment with healthy habits are still under construction [59, 62, 63]. For consumption to occur, material resources must be available when 
Table 5 Association between perceived availability of healthy food and frequency of consumption of vegetables - ELSA-Brasil, 2008-2010

\begin{tabular}{|c|c|c|c|c|c|c|}
\hline \multirow[t]{3}{*}{ Variables } & \multicolumn{6}{|c|}{ Consumption of vegetables $^{\mathrm{a}}$} \\
\hline & \multicolumn{2}{|c|}{ Weekly } & \multicolumn{2}{|l|}{ Daily } & \multicolumn{2}{|l|}{ High } \\
\hline & $\mathrm{OR}$ & $\mathrm{Cl}(95 \%)$ & OR & $\mathrm{Cl}(95 \%)$ & $\mathrm{OR}$ & $\mathrm{Cl}(95 \%)$ \\
\hline \multicolumn{7}{|l|}{ Model 1} \\
\hline Neighbourhood availability of healthy foods (better) & 1.11 & $0.99-1.23$ & 1.37 & $1.25-1.52$ & 1.57 & $1.39-1.77$ \\
\hline \multicolumn{7}{|l|}{ Model 2: Model $1+$ age } \\
\hline Neighbourhood availability of healthy foods (better) & 1.10 & $0.98-1.22$ & 1.34 & $1.21-1.48$ & 1.53 & $1.35-1.73$ \\
\hline Age & 1 & $1-1.01$ & 1.01 & $1.01-1.02$ & 1.02 & $1.01-1.02$ \\
\hline \multicolumn{7}{|l|}{ Model 3: Model $2+$ gender } \\
\hline Neighbourhood availability of healthy foods (better) & 1.10 & $0.98-1.22$ & 1.34 & $1.21-1.48$ & 1.53 & $1.35-1.73$ \\
\hline Age & 1 & $1-1.01$ & 1.02 & $1.01-1.02$ & 1.02 & $1.01-1.02$ \\
\hline Gender (male) & 0.76 & $0.68-0.85$ & 0.52 & $0.47-0.58$ & 0.44 & $0.39-0.5$ \\
\hline \multicolumn{7}{|l|}{ Model 4: Model 3 + education } \\
\hline Neighbourhood availability of healthy foods (better) & 1.09 & $0.98-1.22$ & 1.3 & $1.17-1.44$ & 1.49 & $1.31-1.68$ \\
\hline Age & 1.01 & $1-1.01$ & 1.02 & $1.01-1.03$ & 1.02 & $1.01-1.03$ \\
\hline Gender (male) & 0.77 & $0.69-0.86$ & 0.53 & $0.48-0.59$ & 0.44 & $0.39-0.5$ \\
\hline Education (Elementary complete) & 1 & $0.78-1.29$ & 1.16 & $0.9-1.48$ & 0.99 & $0.72-1.35$ \\
\hline (Secondary complete) & 1.16 & $0.94-1.43$ & 1.78 & $1.45-2.18$ & 1.21 & $0.94-1.56$ \\
\hline (University graduate) & 1.57 & $1.23-1.99$ & 2.85 & $2.27-3.58$ & 1.7 & $1.28-2.26$ \\
\hline (Postgraduate) & 1.85 & $1.49-2.31$ & 5.45 & $4.41-6.73$ & 3.65 & $2.82-4.72$ \\
\hline \multicolumn{7}{|l|}{ Model 5: Model $4+$ standardised income score } \\
\hline Neighbourhood availability of healthy foods (better) & 1.08 & $0.97-1.21$ & 1.28 & $1.16-1.42$ & 1.47 & $1.30-1.67$ \\
\hline Age & 1.01 & $1-1.01$ & 1.01 & $1.01-1.02$ & 1.02 & $1.01-1.02$ \\
\hline Gender (male) & 0.78 & $0.69-0.87$ & 0.54 & $0.49-0.6$ & 0.44 & $0.39-0.5$ \\
\hline Education (Elementary complete) & 0.99 & $0.77-1.27$ & 1.12 & $0.87-1.43$ & 0.96 & $0.7-1.32$ \\
\hline (Secondary complete) & 1.12 & $0.9-1.38$ & 1.62 & $1.32-1.99$ & 1.13 & $0.88-1.46$ \\
\hline (University graduate) & 1.41 & $1.1-1.81$ & 2.29 & $1.81-2.91$ & 1.45 & $1.08-1.94$ \\
\hline (Postgraduate) & 1.56 & $1.22-2$ & 3.83 & $3.04-4.84$ & 2.81 & $2.12-3.73$ \\
\hline Per capita income z-score & 1.14 & $1.05-1.25$ & 1.30 & $1.21-1.41$ & 1.23 & $1.12-1.34$ \\
\hline
\end{tabular}

Reference category: rarely consumed (once a week or less). ${ }^{2}$ weekly (two to four times a week); daily (once a day/five to six times a week); high (twice or more a day) Bold data are statistically significative

supply is not free (e.g., public spaces for practising physical activity) and foods are not accessibly priced. In addition to the positive associations between education, income and greater consumption of fruit and vegetables found in our study, a recent survey in São Paulo found that access to healthy foods was greater in areas of the city with medium and high socioeconomic status [64]. Another mechanism that may explain the relation between objective conditions that favour healthy habits and such habits actually being practised is the awareness that they are important and individual perceptions that these characteristics are present in the neighbourhood [16]. The availability of such structures in the neighbourhood makes for greater access and may kindle interest in changing habits relating to health and wellbeing. However, these relations are more complex. For instance, a study by Cummins et al. [65] in Glasgow, Scotland, showed that after a new supermarket was built in an area where there had been no such establishment, the local population's consumption of fruit and vegetables showed no change, despite distribution of purchase vouchers. One of the explanations offered is that the population did not 'identify or recognise themselves' as consumers in that environment. Accordingly, availability seems to be mediated by values and cultural habits, as well as by diverse demographic and psychological characteristics [18].

It is worth noting that in countries like Brazil people who can afford to live in more expensive neighbourhoods also tend to have access to a series of facilities including greater availability of healthy foods and services, public and private spaces and more secure conditions 
for practising physical activity [64]. In our study population, environments perceived as better for engaging in physical activity and perceived better availability of healthy food were also more frequent among individuals with better education and higher per capita family income. However, the perception of neighbourhood showed a significant association with both behaviour types studied, even after adjustment for these characteristics, suggesting it is affected by context, as well as by individual socioeconomic status.

The strengths of our study are related primarily to the ELSA-Brasil itself, the first cohort study of cardiovascular diseases and diabetes in Latin America, which placed major emphasis on the social and contextual determinants of health. Given that most other studies have been conducted in high-income countries, our results contribute to understanding the associations of interest in different context. In addition, as it is multicentre, it is possible to derive results relating to some 15,000 individuals resident in six metropolises located in differing regions of Brazil (South, Southeast and Northeast). We also used a structured, validated questionnaire similar to the one applied in one of the main cohort studies of cardiovascular diseases [18], making it easier to compare results.

However, some potential limitations of our analysis merit consideration. Both cross-sectional and longitudinal analyses [66] may display migration bias from physically active individuals seeking to live in places favourable to such habits and the same occurring in relation to the availability of healthy food $[47,67]$. We were unable to control for self-selection to the neighbourhood. However, it must be acknowledged that most people in Brazil do not choose where they live; to some extent, they are chosen (or excluded) by housing prices in the various different areas of the city. To some extent, that is a type of bias because "high-class" areas are also the ones that offer the best objective conditions for acquiring and maintaining healthy habits. It is thus unlikely that people made a priority of choosing their place of residence specifically with a view to healthy habits, especially some 17 years ago (our population's mean time of residence in the neighbourhood), when the relation between healthy habits, health and wellbeing had not yet been popularised in Brazil. Similar to other cohort studies $[68,69]$, our sample does not represent the Brazilian population. Mean family income and education attainment in ELSA-Brasil are higher than in Brazilian population. However, there is enough variability regarding socioeconomic position, allowing for comparisons among groups. Finally, we cannot exclude same source bias (i.e. possibility that people with better diets are more aware of healthy foods, same for physical activity). Ongoing analyses considering aggregates across areas will further elucidate this possibility.

\section{Conclusions}

Perceived walkability and neighbourhood availability of healthy food were independently associated with the practice of physical activity and diet quality, respectively. Those results reinforce evidence that developing healthy habits does not depend solely on the individual [8], underlining the importance of neighbourhood-level public policies to changing and maintaining health-related habits. In countries with considerable social inequality, public policies constitute one of the key means of creating objective conditions for embracing and maintaining such behaviour. How relations between residential context and behaviour develop over time will be addressed by future longitudinal analyses of the ELSA-Brasil cohort. In addition, in connection with that study, it will be possible to experiment by combining different approaches to evaluating context, including geographical location measurements, other indicators extracted from secondary data sets and individual perceptions, which are strategies that have been little used simultaneously in countries like Brazil.

\section{Additional file}

Additional file 1: Items included in the neighbourhood scales. This additional file presents the items included in the neighbourhood scales, which report the participants' perception of the walking environment and availability of healthy foods. (PDF $40 \mathrm{~kb}$ )

\section{Abbreviations}

ELSA, Estudo Longitudinal de Saúde do Adulto (Longitudinal Study of Adult Health); HDI, human development index; IPAQ, International Physical Activity Questionnaire; MESA, multi-ethnic study of atherosclerosis; PPP, purchasing power parity

\section{Acknowledgements}

The authors thank the staff and participants of the Elsa Study for their important contributions.

\section{Funding}

The ELSA-Brasil baseline study was supported by Brazil's Ministry of Health (Department of Science and Technology) and Ministry of Science and Technology (Study and Project Funding agency-FINEP and National Research Council-CNPq) (grants 01060010.00 RS, 01060212.00 BA, 01060300.00 ES, 01060278.00 MG, 01060115.00 SP, and 01060071.00 RJ). The funding source had no influence over the study design, data collection, analysis and interpretation, writing the paper, or the decision to publish.

\section{Availability of data and materials}

Data Availability Statement: The data used in this study are available for research proposal on request to the ELSA's Datacenter and to the ELSA's Publications Committee (publiELSA). Additional information can be obtained from the ELSA's Datacenter (estatisticaelsa@ufrgs.br) and from the ELSA Coordinator from the Research Center of Rio de Janeiro (rohgriep@ioc.fiocruz.br).

\section{Authors' contributions}

DC participated in study design, statistical analysis, data interpretation and drafted the manuscript. LC and RHG participated in data interpretation and helped writing the manuscript. AN and DPC performed the statistical analysis and data interpretation. MF, LG, IB, EA participated in study design and contributed with intellectual content to the paper. ADR contributed with intellectual content to the paper. SS participated in the adaptation of the neighbourhood scales, performed the statistical analysis, data interpretation 
and helped write the manuscript. All authors have read and approved the final manuscript.

\section{Competing interests}

The authors declare that they have no competing interests.

\section{Consent for publication}

Not applicable.

\section{Ethics approval and consent to participate}

The study was approved by the Research and Ethics Committees of the institutions involved - Oswaldo Cruz Foundation and the Federal universities of Bahia, Espirito Santo, Minas Gerais, and Rio Grande do Sul; and the University of Sao Paulo. All participants signed declarations of informed consent.

\section{Author details}

${ }^{1}$ Escola Nacional de Saúde Pública, Fundação Oswaldo Cruz, Rio de Janeiro, RJ, Brazil. ${ }^{2}$ Programa de Computação Científica, Fundação Oswaldo Cruz, Rio de Janeiro, RJ, Brazil. ${ }^{3}$ Instituto Oswaldo Cruz, Fundação Oswaldo Cruz, Rio de Janeiro 21040-360, RJ, Brazil. "Escola de Nutrição, Universidade Federal de Ouro Preto, Ouro Preto, MG, Brazil. ${ }^{5}$ Hospital Universitário, Universidade de São Paulo, São Paulo, SP, Brazil. ${ }^{6}$ Departamento de Nutrição, Universidade Federal do Espírito Santo, Vitória, Espírito Santo, Brazil. ${ }^{7}$ Instituto de Saúde Coletiva, Universidade Federal da Bahia, Salvador, Bahia, Brazil. ${ }^{8}$ School of Public Health, Drexel University, Philadelphia, PA, USA. ${ }^{9}$ Fundação Oswaldo Cruz, Rio de Janeiro, RJ, Brazil.

\section{Received: 19 June 2015 Accepted: 5 August 2016} Published online: 09 August 2016

\section{References}

1. Brazil Health Ministery. Vigitel Brasil 2012: vigilância de fatores de risco e proteção para doenças crônicas por inquérito telefônico. Brasília: Ministério da Saúde; 2013. 136 p. il. B.

2. Hankinson AL, Daviglus ML, Bouchard C, Carnethon M, Lewis CE, Schreiner PJ, et al. Maintaining a high physical activity level over 20 years and weight gain. JAMA. 2010;304:2603-10.

3. Bouchard C, Blair SN, Haskell WL, editors. Physical activity and health. 2nd ed. Champaign: Human Kinetics; 2012.

4. Wang L, van Belle G, Kukull WB, Larson EB. Predictors of functional change: a longitudinal study of nondemented people aged 65 and older. J Am Geriatr Soc. 2002;50:1525-34

5. Larson EB, Wang L, Bowen JD, McCormick WC, Teri L, Crane P, et al. Exercise is associated with reduced risk for incident dementia among persons 65 years of age and older. Ann Intern Med. 2006;144:73-81.

6. Mokdad AH, Bowman BA, Ford ES, Vinicor F, Marks JS, Koplan JP. The continuing epidemics of obesity and diabetes in the United States. JAMA. 2001;286:1195-200.

7. Mokdad AH, Marks JS, Stroup DF, Gerberding JL. Actual causes of death in the United States, 2000. JAMA. 2004;291:1238-45.

8. Abel T, Frohlich KL. Capitals and capabilities: linking structure and agency to reduce health inequalities. Soc Sci Med. 2012;74:236-44.

9. Samuel LJ, Dennison Himmelfarb CR, Szklo M, Seeman TE, Echeverria SE, Diez Roux AV. Social engagement and chronic disease risk behaviors: the Multi-Ethnic Study of Atherosclerosis. Prev Med. 2015;71:61-6.

10. Cockerham WC. Health Lifestyle Theory and the Convergence of Agency and Structure. J. Health Soc. Behav. [Internet]. 2005 [cited 2016 Jun 18]:46: 51-67. Available from: http://hsb.sagepub.com/cgi/doi/10.1177/ 002214650504600105 . Accessed 21 May 2015.

11. Berke EM, Koepsell TD, Moudon AV, Hoskins RE, Larson EB. Association of the built environment with physical activity and obesity in older persons. Am J Public Health. 2007;97:486-92.

12. Gerber $Y$, Benyamini $Y$, Goldbourt $U$, Drory $Y$, for the Israel Study Group on First Acute Myocardial Infarction. Neighborhood Socioeconomic Context and Long-Term Survival After Myocardial Infarction. Circulation [Internet]. 2010 [cited 2016 Jun 18];121:375-83. Available from: http://circ.ahajournals. org/cgi/doi/10.1161/CIRCULATIONAHA.109.882555. Accessed 5 Dec 2014.

13. Auchincloss AH, Diez Roux AV, Mujahid MS, Shen M, Bertoni AG, Carnethon MR. Neighborhood resources for physical activity and healthy foods and incidence of type 2 diabetes mellitus: the Multi-Ethnic study of Atherosclerosis. Arch Intern Med. 2009:169:1698-704.

14. Pickett KE, Pearl M. Multilevel analyses of neighbourhood socioeconomic context and health outcomes: a critical review. J Epidemiol Community Health. 2001;55:111-22.

15. Diez Roux AV, Evenson KR, McGinn AP, Brown DG, Moore L, Brines S, et al. Availability of recreational resources and physical activity in adults. Am J Public Health. 2007:97:493-9.

16. Morland K, Wing S, Diez RA. The contextual effect of the local food environment on residents' diets: the atherosclerosis risk in communities study. Am J Public Health. 2002;92:1761-7.

17. Moore LV, Diez Roux AV, Nettleton JA, Jacobs DR, Franco M. Fast-food consumption, diet quality, and neighborhood exposure to fast food: the multi-ethnic study of atherosclerosis. Am J Epidemiol. 2009;170:29-36.

18. Mujahid MS, Diez Roux AV, Morenoff JD, Raghunathan T. Assessing the measurement properties of neighborhood scales: from psychometrics to ecometrics. Am J Epidemiol. 2007;165:858-67.

19. Moore LV, Diez Roux AV, Nettleton JA, Jacobs DR. Associations of the local food environment with diet quality-a comparison of assessments based on surveys and geographic information systems: the multi-ethnic study of atherosclerosis. Am J Epidemiol. 2008;167:917-24.

20. Wen M, Hawkley LC, Cacioppo JT. Objective and perceived neighborhood environment, individual SES and psychosocial factors, and self-rated health: an analysis of older adults in Cook County, Illinois. Soc Sci Med. 2006;63:2575-90.

21. Hale L, Hill TD, Friedman E, Nieto FJ, Galvao LW, Engelman CD, et al. Perceived neighborhood quality, sleep quality, and health status: evidence from the Survey of the Health of Wisconsin. Soc Sci Med. 2013;79:16-22.

22. Kawachi I, Berkman LF, editors. Neighborhoods and health. Oxford; New York: Oxford University Press; 2003.

23. Aquino EM, Barreto SM, Bensenor IM, Carvalho MS, Chor D, Duncan BB, et al. Brazilian Longitudinal Study of Adult Health (ELSA-Brasil): objectives and design. AmJ Epidemiol. 2012;175:315-24.

24. Schmidt MI, Duncan BB, Mill JG, Lotufo PA, Chor D, Barreto SM, et al. Cohort Profile: Longitudinal Study of Adult Health (ELSA-Brasil). Int. J. Epidemiol. 2014; 44:24585730.

25. Bensenor IM, Griep RH, Pinto KA, Faria CP de, Felisbino-Mendes M, Caetano El, et al. [Routines of organization of clinical tests and interviews in the ELSA-Brasil investigation center]. Rev Saúde Pública. 2013:47 Suppl 2:37-47

26. Chor D, Alves MG de M, Giatti L, Cade NV, Nunes MA, Molina M del CB, et al. [Questionnaire development in ELSA-Brasil: challenges of a multidimensional instrument]. Rev Saúde Pública. 2013;47 Suppl 2:27-36

27. Santos SM, Griep RH, Cardoso LO, Alves MG de M, Fonseca M de JM da, Giatti $L$, et al. [Cross-cultural adaptation and reliability of measurements on self-reported neighborhood characteristics in ELSA-Brasil]. Rev Saúde Pública. 2013:47 Suppl 2:122-30.

28. Sampson RJ, Raudenbush SW, Earls F. Neighborhoods and violent crime: a multilevel study of collective efficacy. Science. 1997:277:918-24.

29. Echeverria SE, Diez-Roux AV, Link BG. Reliability of self-reported neighborhood characteristics. J Urban Health Bull N Y Acad Med. 2004:81:682-701.

30. Lee PH, Macfarlane DJ, Lam TH, Stewart SM. Validity of the International Physical Activity Questionnaire Short Form (IPAQ-SF): a systematic review. Int J Behav Nutr Phys Act. 2011:8:115

31. Thomaz PMD, da Costa THM, da Silva EF, Hallal PC. Factors associated with physical activity in adults in Brasília, Central-West Brazil. Rev Saude Publica. 2010;44:894-900.

32. Haskell WL, Lee I-M, Pate RR, Powell KE, Blair SN, Franklin BA, et al. Physical activity and public health: updated recommendation for adults from the American College of Sports Medicine and the American Heart Association. Med Sci Sports Exerc. 2007;39:1423-34.

33. O'Donovan G, Blazevich AJ, Boreham C, Cooper AR, Crank H, Ekelund U, et al. The $A B C$ of Physical Activity for Health: A consensus statement from the British Association of Sport and Exercise Sciences. J. Sports Sci. [Internet]. 2010 [cited 2016 Jul 3];28:573-91. Available from: http://www.tandfonline.com/doi/ abs/10.1080/02640411003671212. Accessed 5 Dec 2014.

34. World Health Organization. Global recommendations on physical activity for health. Geneva: World Health Organization; 2010.

35. Monteiro CA, Moura EC, Jaime PC, Claro RM. [Validity of food and beverage intake data obtained by telephone survey]. Rev Saude Publica. 2008:42:582-9.

36. World Bank. PPP conversion factor, private consumption (LCU per international \$) [Internet]. 2012 [cited 2013 May 15]. Available from: http://data.worldbank.org/indicator/PA.NUS.PRVT.PP. Accessed 10 Apr 2014. 
37. Team RC. R: A Language and Environment for Statistical Computing [Internet]. Vienna: R Foundation for Statistical Computing; 2013. Available from: http://www.R-project.org/.

38. Giles-Corti B, Donovan RJ. The relative influence of individual, social and physical environment determinants of physical activity. Soc Sci Med. 2002; 54:1793-812.

39. Duncan M, Mummery K. Psychosocial and environmental factors associated with physical activity among city dwellers in regional Queensland. Prev Med. 2005;40:363-72.

40. Kerr J, Emond JA, Badland H, Reis R, Sarmiento O, Carlson J, et al. Perceived Neighborhood Environmental Attributes Associated with Walking and Cycling for Transport among Adult Residents of 17 Cities in 12 Countries: The IPEN Study. Environ Health Perspect. 2016;124:290-8.

41. Evenson KR, Block R, Diez Roux AV, McGinn AP, Wen F, Rodríguez DA. Associations of adult physical activity with perceived safety and policerecorded crime: the Multi-ethnic Study of Atherosclerosis. Int J Behav Nutr Phys Act. 2012;9:146

42. Sallis JF, Bowles HR, Bauman A, Ainsworth BE, Bull FC, Craig CL, et al. Neighborhood environments and physical activity among adults in 11 countries. Am J Prev Med. 2009;36:484-90.

43. Ding D, Adams MA, Sallis JF, Norman GJ, Hovell MF, Chambers CD, et al. Perceived neighborhood environment and physical activity in 11 countries: do associations differ by country? Int J Behav Nutr Phys Act. 2013;10:57.

44. Lee I-M, Ewing R, Sesso HD. The built environment and physical activity levels: the Harvard Alumni Health Study. Am J Prev Med. 2009;37:293-8.

45. Martin KR, Shreffler J, Schoster B, Callahan LF. Associations of perceived neighborhood environment on health status outcomes in persons with arthritis. Arthritis Care Res. 2010;62:1602-11.

46. Boslaugh SE, Luke DA, Brownson RC, Naleid KS, Kreuter MW. Perceptions of neighborhood environment for physical activity: is it "who you are" or "where you live"? N Y Acad Med. 2004;81:671-81.

47. Jongeneel-Grimen B, Busschers W, Droomers M, van Oers HAM, Stronks K, Kunst AE. Change in neighborhood traffic safety: does it matter in terms of physical activity? PLoS ONE. 2013:8:e62525.

48. Jongeneel-Grimen B, Droomers M, van Oers HAM, Stronks K, Kunst AE. The relationship between physical activity and the living environment: a multilevel analyses focusing on changes over time in environmental factors. Health Place. 2014:26:149-60.

49. PNUD. Atlas do desenvolvimento humano no Brasil.2013 [Internet]. 2013 [cited 2014 Nov 15]. Available from: http://www.atlasbrasil.org.br/2013. Accessed 5 Dec 2014.

50. Fermino RC, Reis RS, Hallal PC, de Farias Júnior JC. Perceived environment and public open space use: a study with adults from Curitiba, Brazil. Int J Behav Nutr Phys Act. 2013;10:35.

51. Thielman J, Rosella L, Copes R, Lebenbaum M, Manson H. Neighborhood walkability: Differential associations with self-reported transport walking and leisure-time physical activity in Canadian towns and cities of all sizes. Prev. Med. [Internet]. 2015 [cited 2016 Jul 3];77:174-80. Available from: http:// linkinghub.elsevier.com/retrieve/pii/S009174351500170X. Accessed 6 Nov 2015.

52. Liao Y, Wang $\mathrm{I}-\mathrm{T}$, Hsu H-H, Chang S-H. Perceived Environmental and Personal Factors Associated with Walking and Cycling for Transportation in Taiwanese Adults. Int. J. Environ. Res. Public. Health [Internet]. 2015 [cited 2016 Jul 3];12: 2105-19. Available from: http://www.mdpi.com/1660-4601/12/2/2105/. Accessed 11 Jun 2016.

53. Kelley EA, Kandula NR, Kanaya AM, Yen IH. Neighborhood Walkability and Walking for Transport Among South Asians in the MASALA Study. J Phys Act Health. 2016;13:514-9.

54. Hallal PC, Reis RS, Parra DC, Hoehner C, Brownson RC, Simões EJ. Association between perceived environmental attributes and physical activity among adults in Recife, Brazil. J Phys Act Health. 2010;7 Suppl 2:S213-22.

55. Corseuil MW, Schneider IJC, Silva DAS, Costa FF, Silva KS, Borges L, et al. Perception of environmental obstacles to commuting physical activity in Brazilian elderly. Prev. Med. [Internet]. 2011 [cited 2016 Jul 3];53:289-92. Available from: http://linkinghub.elsevier.com/retrieve/pii/ S0091743511002829. Accessed 26 May 2016.

56. Siqueira Reis R, Hino AAF, Ricardo Rech C, Kerr J, Curi Hallal P. Walkability and Physical Activity. Am. J. Prev. Med. [Internet]. 2013 [cited 2016 Jul 3];45: 269-75. Available from: http://linkinghub.elsevier.com/retrieve/pii/ S0749379713003413. Accessed 5 Dec 2014.
57. Amorim TC, Azevedo MR, Hallal PC. Physical activity levels according to physical and social environmental factors in a sample of adults living in South Brazil. J Phys Act Health. 2010;7 Suppl 2:S204-12.

58. Jaime PC, Duran AC, Sarti FM, Lock K. Investigating environmental determinants of diet, physical activity, and overweight among adults in Sao Paulo, Brazil. J Urban Health Bull N Y Acad Med. 2011;88:567-81.

59. Caspi CE, Sorensen G, Subramanian SV, Kawachi I. The local food environment and diet: a systematic review. Health Place. 2012;18:1172-87.

60. Gustafson AA, Sharkey J, Samuel-Hodge CD, Jones-Smith J, Folds MC, Cai J, et al. Perceived and objective measures of the food store environment and the association with weight and diet among low-income women in North Carolina. Public Health Nutr. 2011;14:1032-8.

61. Pearson T, Russell J, Campbell MJ, Barker ME. Do "food deserts" influence fruit and vegetable consumption?-A cross-sectional study. Appetite. 2005; 45:195-7.

62. Glanz K, Sallis JF, Saelens BE, Frank LD. Healthy nutrition environments: concepts and measures. Am J Health Promot AJHP. 2005;19:330-3. ii.

63. Kremers SPJ, de Bruijn G-J, Visscher TLS, van Mechelen W, de Vries NK, Brug J. Environmental influences on energy balance-related behaviors: a dual-process view. Int J Behav Nutr Phys Act. 2006;3:9.

64. Duran AC, Diez Roux AV, Latorre M do RDO, Jaime PC. Neighborhood socioeconomic characteristics and differences in the availability of healthy food stores and restaurants in Sao Paulo, Brazil. Health Place. 2013;23:39-47

65. Cummins S. Neighbourhood food environment and diet: time for improved conceptual models? Prev Med. 2007:44:196-7.

66. Jokela M. Are neighborhood health associations causal? A 10-year prospective cohort study with repeated measurements. Am J Epidemiol. 2014;180:776-84.

67. Boone-Heinonen J, Gordon-Larsen P, Guilkey DK, Jacobs DR, Popkin BM. Environment and Physical Activity Dynamics: The Role of Residential Selfselection. Psychol Sport Exerc. 2011;12:54-60.

68. Marmot M, Brunner E. Cohort Profile: the Whitehall II study. Int J Epidemiol. 2005:34:251-6.

69. Willett WC, Sampson L, Stampfer MJ, Rosner B, Bain C, Witschi J, et al. Reproducibility and validity of a semiquantitative food frequency questionnaire. Am J Epidemiol. 1985;122:51-65.

\section{Submit your next manuscript to BioMed Central and we will help you at every step:}

- We accept pre-submission inquiries

- Our selector tool helps you to find the most relevant journal

- We provide round the clock customer support

- Convenient online submission

- Thorough peer review

- Inclusion in PubMed and all major indexing services

- Maximum visibility for your research

Submit your manuscript at www.biomedcentral.com/submit 